\title{
Algunas ideas sobre el delito de trata de personas y el delito de explotación de menores de edad en el derecho penal colombiano. A propósito de la Sentencia C-464 de 2014 de la Corte Constitucional
} Some ideas on the crime of trafficking in human beings and the
crime of exploitation of minors in the Colombian criminal law.
Regarding the Judgment C-464 of 2014 of the Constitutional Court

Alfredo Alpaca Pérez.

Abogado por la Pontificia Universidad Católica del Perú; máster en Derecho Penal por la Universidad de Salamanca,

España; doctorado (en curso) en Derecho en el Programa de Doctorado Responsabilidad Jurídica. Estudio Multidisciplinar de la Universidad de León, España. Investigador contratado predoctoral de la Universidad de León. Correo electrónico: alfredo.alpaca@hotmail.com

Dhyana Stephania Serrano Suárez

Abogada por la Universidad Santo Tomás Bucaramanga (Col.); especialista en Derecho Constitucional por la Universidad Libre de Colombia; máster en Derecho Penal; doctorado (en curso) en Derecho en el Programa de Doctorado Estado de Derecho y Gobernanza Global por la Universidad de Salamanca, España.

Correo electrónico: stephania.serrano@gmail.com

Resumen

En el siguiente artículo se proponen algunos lineamientos interpretativos acerca de la posible relación concursal entre los delitos de trata de personas y explotación de menores en la legislación penal colombiana, apartándonos en muchos aspectos de la reciente jurisprudencia constitucional al respecto. En ese sentido, se abordarán diversos asuntos problemáticos: primero, desde el punto de vista de la regulación internacional y, posteriormente, mediante el análisis de la estructura de los tipos penales correspondientes (artículo 188-A del Código Penal y artículo 93 de la Ley 1453, respectivamente), lo que permitirá determinar la delimitación y los alcances de cada uno de ellos. La principal idea que se defiende en el artículo consiste en sostener que el delito de trata de personas ofrece una protección jurídico-penal satisfactoria a los menores de edad en los escenarios en los que se verifiquen actos referidos a su explotación, por lo que el delito de explotación de menores (por varias razones que se exponen) resultaría inaplicable.

Palabras clave: Trata de personas, explotación de menores de edad, mendicidad, concurso aparente de leyes.

Abstract

In the following article we propose some interpretive lines about the alleged relationship between the crimes of trafficking in persons and the exploitation of children in the colombian criminal law, therefore, we will diverge in many aspects of the recent constitutional case law. In this respect, we will address various problematic issues: first, from an international perspective and then, by analysing the internal structure of the corresponding criminal offences (article 188-A of the Criminal Code and article 93 of the Law $\mathrm{N}^{\circ} 1453$, respectively), what will allow the demarcation and the scope of the aforementioned crimes. The main idea of the contribution is that the crime of trafficking in persons offers a satisfactory legal protection to minors in the cases in which they are exploited. Therefore, the crime of exploitation of children (due to various arguments explained in the article) would be not applicable.

Keywords: Human trafficking, exploitation of children, mendicancy, concurrence of crimes.

Recibido: 31 de julio de 2015; Aprobado: 16 de septiembre de 2015 


\section{Résumé}

Dans l'article suivant énumère quelques conseils d'interprétation sur la relation de l'insolvabilité possible entre les crimes de la traite et de l'exploitation des enfants dans le droit pénal colombien, détournant dans de nombreux aspects de la récente jurisprudence constitutionnelle sont proposées. À cet égard, plusieurs questions problématiques seront abordées: d'abord, du point de vue de la réglementation internationale, puis en analysant la structure des infractions pertinentes (article 188-A du Code pénal et l'article 93 de la Loi 1453, respectivement), qui déterminera la définition et la portée de chacun. L'idée principale préconisée dans l'article est de faire valoir que le crime de traite des êtres humains fournit un mineurs satisfaisants dans les scénarios dans lesquels les actes relatifs à son fonctionnement sont vérifiées une protection juridique en matière pénale, de sorte que le crime l'exploitation des enfants (pour diverses raisons :) inapplicable.

Mots-clés: traite des êtres humains, l'exploitation des mineurs, la mendicité, les lois de la concurrence apparentes. 


\section{Algunas ideas sobre el delito de trata de personas y el delito de explotación de menores de edad en el derecho penal colombiano. A propósito de la Sentencia C-464 de 2014 de la Corte Constitucional ${ }^{*}$}

Alfredo Alpaca Pérez

Dhyana Stephania Serrano Suárez

\section{INTRODUCCIÓN}

Mediante Sentencia C-464 de 2014, la Corte Constitucional resolvió la demanda de inconstitucionalidad interpuesta contra el artículo 93 de la Ley 1453 de 2011, que incorpora en la legislación nacional el delito de explotación de menores de edad ${ }^{1}$. La demanda se sustentó esencialmente en tres argumentos: primero, que la conducta prescrita en el artículo 93 de la Ley 1453 de 2011, relativo a la explotación de menores, genera una confusión típica con el artículo 188-A del Código Penal, en el que se encuentra tipificado el delito de trata de personas ${ }^{2}$, debiendo entenderse que, en la medida que el tipo penal demandado se encuentra subsumido totalmente por el precepto del Código Penal (el elemento subjetivo del delito de trata de personas

* $\quad$ Proyecto de Investigación DER2013-47511-R, denominado «Las garantías penales como límite y guía en la solución de problemas penales complejos: la necesidad de evitar atajos»; financiado por el Ministerio de Economía y Competitividad de España (en el marco de la «Convocatoria 2013 Proyectos I+D+I- Programa Estatal de Investigación, Desarrollo e Innovación orientada a los retos de la sociedad»), Investigador Principal Prof. Dr. Miguel Díaz y García Conlledo (Catedrático de Derecho penal de la Universidad de León, España). Alfredo Alpaca Pérez, investigador; Dhyana Stephania Serrano Suárez, miembro del equipo de trabajo

1 El artículo demandado, contenido en el art. 93, capítulo IV, relativo a "medidas para garantizar la seguridad ciudadana relacionadas con el Código de la Infancia y la Adolescencia" de la Ley 1453 de 2011, "Por medio de la cual se reforma el Código Penal, el Código de Procedimiento Penal, el Código de Infancia y Adolescencia, las reglas sobre extinción de dominio y se dictan otras disposiciones en materia de seguridad" (conocido comúnmente como "Ley de seguridad ciudadana").

2 El delito de trata de personas está tipificado en el art. 188-A del Código Penal, que fue adicionado por el art. 2 de la Ley 747 de 2002 y modificado por el art. 3 de la Ley 985 de 2005. 
permitiría entender como subsumido en este al delito de explotación de menores) se produciría una vulneración del principio de igualdad (art. 13 de la Constitución), pues el artículo cuestionado, referido a menores de edad, establecería una protección inferior (pena de 3 a 7 años para quien explote a los menores de edad) en comparación a la que ofrece el art. 188-A del Código Penal (pena de 13 a 23 años, para quien explote a un adulto) ${ }^{3}$; segundo, que la vigencia del art. 93 de la Ley 1453 de 2011 representaría una vulneración al principio de non bis in idem, pues en la medida que la explotación de menores se subsume en el delito de trata de personas, existirían dos sanciones distintas para la misma conducta; y, tercero, que la expresión "mendigue con menores de edad" contemplada en el art. 93 de la Ley 1453 de 2011 vulneraría el debido proceso, al pretender incriminar la mendicidad con menores de edad, cuestión que no sería acorde con la realidad del país, pues muchas familias, por la situación de extrema pobreza en la que viven, optan por la mendicidad como único medio de subsistencia sin que ello implique necesariamente tener la intención de explotar económicamente a sus hijos ${ }^{4}$.

Pues bien, la Corte Constitucional, después de analizar el contenido y alcances de los arts. 93 de la Ley 1453 y 188-A y 188-B del Código Penal, señaló que tales figuras delictivas

no tienen identidad típica por cuanto se diferencian en cuatro puntos cardinales. En primer lugar, por los sujetos pasivos de ambos tipos penales: en el artículo demandado -explotación de menores-, el sujeto pasivo es determinado, pues recae exclusivamente sobre menores de edad, mientras que en la trata de personas el sujeto pasivo puede ser cualquier persona, es decir, es indeterminado. En segundo lugar, aunque ambos delitos comprenden conductas alternativas, los verbos rectores son completamente distintos: la explotación de menores reprocha al que utilice, instrumentalice, comercialice o mendigue con menores de edad, por su parte, la trata de personas sanciona a quien capte, traslade, acoja o reciba a cualquier persona. En tercer lugar, el tipo penal de trata de personas se diferenciaría de la

3 Al respecto, en la sentencia se señala lo siguiente: "Según la actora, la nueva regulación es irrazonable y desproporcionada ya que el menor de edad por su condición de especial protección y debilidad manifiesta debería contar con una mayor protección que el adulto. En su concepto, resulta reprochable constitucionalmente que" "quien en condición de superioridad o confianza se aprovecha del sufrimiento de pesar que produce un niño mendigando, y por tanto, resulta necesario que tal conducta reprochable sea sancionada penalmente atendiendo su gravedad, de tal forma que se castigue con más severidad al que mendiga con un menor de edad, que al que mendiga utilizando un adulto' -folio 13-. Más adelante, indica otra presunta desigualdad ya que el nuevo tipo penal puede resultar excarcelable mientras el contenido en el art. 188A del Código Penal no".

4 La demandante afirma que "un padre o madre en las condiciones antes dichas que sea sorprendido ejerciendo la mendicidad propia pero en compañía de sus hijos menores de edad, puede ser judicializado por el delito de mendicidad ajena, constituyéndose esto en una forma de criminalizar la pobreza". La demandante, además, cita la Sentencia C-040 de 2006 en la cual la Corte precisó que es legítimo el ejercicio de la mendicidad propia, pues la misma no afecta derechos de terceros $\mathrm{y}$, por el contrario, puede constituir para la persona un elemento vital de realización personal. 
explotación de menores al contener un ingrediente subjetivo o un carácter intencional distinto del dolo que se emplea para describir la conducta: el delito de trata prevé como elemento adicional una finalidad de explotación, inexistente en el delito de explotación de menores. Finalmente, el delito de trata de personas presenta modalidades de agravación ausentes en el delito de explotación de menores (Sentencia C-464 de 2014. M.P.: Alberto Rojas Ríos).

A partir de los argumentos expuestos, en el presente artículo pretendemos abarcar una serie de asuntos relevantes sobre el delito de trata de personas en el derecho penal colombiano. En primer lugar, intentaremos presentar algunas ideas referidas a los aspectos socio-criminológicos más importantes acerca del fenómeno global de la trata de personas, que han sido tomados en cuenta para formular la estructura básica del delito de trata de personas en el Protocolo de Palermo para Prevenir, Suprimir y Castigar la Trata de Personas, especialmente, la de mujeres y niños, del año 2000. Esto es importante, pues el conocer -aunque sea en términos generales-el trasfondo empírico y la forma básica de criminalización del mencionado fenómeno delictivo puede ayudar a entender por qué y cómo el derecho penal nacional debe proyectarse sobre el mismo en aras de proteger los bienes jurídicos que podrían resultar seriamente comprometidos. En segundo lugar, analizaremos la estructura del delito de trata de personas recogido en el Código Penal colombiano, proponiendo unas interpretaciones específicas de los elementos que integran el aludido precepto. En tercer lugar, desarrollaremos algunas breves apreciaciones críticas sobre el delito de explotación de menores de edad, para así poner en evidencia las complejidades que se desprenden de su configuración típica. Finalmente, expondremos nuestras consideraciones sobre la relación existente entre los delitos antes mencionados, a la luz de la jurisprudencia colombiana y tomando en consideración los argumentos expuestos por nosotros previamente. Podemos aquí adelantar que, desde nuestro punto de vista, el delito de explotación de menores presenta una serie de deficiencias sustanciales que lo revelan como una figura reñida con la vigencia del principio de legalidad, por lo que, ante aquel delito solo cabrían dos opciones: o se modifica el mencionado tipo penal o se deroga su existencia en el ordenamiento jurídico-penal colombiano. En caso de que se considere posible este último escenario, no habría la posibilidad de alegar la existencia de eventuales lagunas de punibilidad, pues -y esta es nuestra idea principal-el delito de trata de personas puede otorgar una protección jurídico-penal satisfactoria a los menores de edad en los escenarios en los que se verifiquen actos orientados a su explotación (en lo que aquí importa, al ejercicio de la mendicidad). 


\section{ALGUNOS ASPECTOS PREVIOS SOBRE EL FENÓMENO DE LA TRATA DE PERSONAS}

Referirnos a la "trata de personas" supone invocar uno de los fenómenos criminales más repudiables en el mundo contemporáneo. En efecto, los términos "trata" o "tráfico", utilizados para darle nombre al fenómeno, aunque a primera vista destaquen su aspecto transaccional, en realidad coadyuvan a entender al referido fenómeno como una forma moderna de esclavitud. Y es que, según entendemos, la trata de personas se caracteriza por dos elementos esenciales: por significar una afectación grave a la libertad y la dignidad humana; y por ser un fenómeno altamente rentable para quienes lo impulsan (Herrero, 2011, p. 382). A partir de ello, no en vano se señala en la actualidad que la trata de personas, junto al tráfico de armas y al tráfico de drogas, es una de las actividades delictivas que generan más ganancias en el mundo (Rodríguez, 2015, p. 58).

Pues bien, en el ámbito internacional, ya desde hace algunos años se han planteado políticas y estrategias de cara al combate del referido fenómeno. Así, el artículo 3 del Protocolo de Palermo, del $2000^{5}$, para Prevenir, Suprimir y Castigar la Trata de Personas, especialmente, la de mujeres y niños, estableció que la trata de personas, como fenómeno criminal, contemplaba la captación, el transporte, el traslado, la acogida o la recepción de personas, a través de la amenaza o el uso de la fuerza $\mathrm{u}$ otras formas de coacción, al rapto, al fraude, al engaño, al abuso de poder o de una situación de vulnerabilidad o de la concesión o recepción de pagos o beneficios para obtener el consentimiento de una persona que tenga autoridad sobre otra, con fines de explotación. La explotación incluirá, como mínimo, la explotación de la prostitución ajena u otras formas de explotación sexual, trabajos o servicios forzados, esclavitud o prácticas similares, servidumbre o extracción de órganos ${ }^{6}$.

Como es posible observar, la definición propuesta por el Protocolo contiene denominaciones ciertamente amplias, con lo que sus contornos, a primera vista, no podrían definirse con precisión (por ejemplo, la "acogida" y la "recepción" o la “amenaza" y la "coacción”). En ese sentido, es importante resaltar que el Protocolo

5 La Convención de las Naciones Unidas para la Delincuencia Organizada y Transnacional, llamada también "Convención de Palermo", fue complementada con tres protocolos (Protocolos de Palermo): Protocolo de las Naciones Unidas para Prevenir, Reprimir y Sancionar la Trata de personas, especialmente mujeres y niños; Protocolo de las Naciones Unidas para el Contrabando de Migrantes por Tierra, Mar y Aire; y, Protocolo de las Naciones Unidas contra la fabricación y el tráfico ilícito de armas de fuego.

6 La redacción original en inglés es como sigue: a) "Trafficking in persons" shall mean the recruitment, transportation, transfer, harbouring or receipt of persons, by means of the threat or use of force or other forms or coercion, of abduction, of fraud, of deception, of the abuse of power or of a position of vulnerability or of the giving or receiving of payments or benefits to achieve the consent of a person having control over other person, for the purpose of exploitation. Exploitation shall include, at a minimum, the exploitation of the prostitution of others or others forms of sexual exploitation, forced labour or services, slavery or practices similar to slavery, servitude or the removal of organs". 
estableció solamente un estándar mínimo de cara al proceso de implementación normativa para llevar a cabo en cada uno de los Estados parte del referido instrumento internacional ${ }^{7}$. De esta manera, se les brinda libertad a los Estados para que puedan concretar las diversas manifestaciones delictivas en la legislación interna, aunque, evidentemente, siguiendo los criterios mínimos recogidos en el Protocolo (Herrero, 2011, p. 338).

Ahora bien, pensamos que, de la redacción propuesta por el Protocolo, es posible afirmar que el fenómeno delictivo de la trata de personas debe entenderse como un proceso, es decir, como una acumulación de actividades concatenadas, cuya realización debe ser interpretada desde la perspectiva de la finalidad, esto es, de un móvil lucrativo (Rodríguez, 2015, p. 62). Ese proceso busca poner a la víctima en una situación de indefensión absoluta, a costa de sus derechos más elementales, para generar a favor de los tratantes un beneficio ilícito y sostenido (Sacha, 2012, p. 119). En ese sentido -y a partir de la definición propuesta por el Protocolo antes aludido-, consideramos posible reconocer que el fenómeno de la trata de personas ostenta tres elementos esenciales: primero, unos elementos de actividad, que serían: la captación, el transporte, el traslado, la acogida o la recepción de personas; segundo, unos elementos de medios, a saber: la amenaza, el uso de la fuerza u otra forma de coacción, el rapto, el fraude, el engaño, el abuso de poder de una situación de vulnerabilidad, o la concesión y la recepción de pagos o beneficios para obtener el consentimiento de una persona que tiene autoridad sobre otra; y, tercero, unos elementos de finalidad, que serían: la explotación (sexual o laboral), la esclavitud, la servidumbre o la extracción de órganos.

Nuevamente, teniendo en cuenta la definición esbozada por el Protocolo -y a partir de ello, los elementos esenciales antes descritos- consideramos posible admitir que el fenómeno de la trata de personas presenta tres fases constitutivas. La primera es la fase de reclutamiento. Esta primera etapa supone, ante todo, la identificación de la posible víctima $\mathrm{y}$, posteriormente, la aproximación a ella -o a la persona que ejerza potestad sobre esta- a efectos de realizarle una propuesta o un ofrecimiento (evidentemente falsos). Aquí puede verificarse a la captación como "elemento de actividad", siendo posible definir aquella como el llamar la atención de una persona o atraerla para un propósito definido. En el fenómeno de la trata de personas, la captación supone el reclutamiento de la víctima, es decir, aproximarse a esta y controlar su voluntad para fines de explotación. Por ello, como es evidente, desde esta primera etapa el agente ya debe contar con el móvil de explotación (aunque aquel no sea necesariamente quien al final la lleve a cabo). El reclutamiento se lleva a cabo de diversas maneras, por lo que aquí también logran identificarse los "elementos de medios" reconocidos anteriormente: la amenaza, el uso de la fuerza u otra forma de coacción, el rapto, el fraude, el engaño, el abuso de poder de una situación de vulnerabilidad, la concesión o recepción de pagos o beneficios (Fernández, 2012, p. 108).

7 El Protocolo de Palermo para Prevenir, Suprimir y Castigar la Trata de Personas, especialmente la de mujeres y niños, fue ratificado por Colombia mediante Ley 800 de 2003 y Ley 985 de 2005. 
La amenaza debe ser concebida como la exteriorización hecha por una persona a otra del propósito de causarle a él, a su familia o a persona allegada un mal o un daño. Por otro lado, el uso de la fuerza debe interpretarse como una forma de violencia física, la cual es aplicada por parte del tratante en la fase de reclutamiento, por ejemplo, al sustraer de manera forzosa a la víctima (Oficina de las Naciones Unidas contra la Droga y el Delito, 2009, p. 13). La coacción supone violencia física, intimidación personal o empleo de fuerza en las cosas para que una persona haga o diga algo. El rapto alude al secuestro de la víctima, es decir, la sustracción y retención de un individuo (Oficina de las Naciones Unidas contra la Droga y el Delito, 2009, p. 15). El engaño supone la creación de hechos total o parcialmente falsos para hacer creer a una persona que algo es cierto. En el fenómeno de la trata de personas el engaño se manifiesta, sobre todo, en la etapa de captación, ya que aquí el tratante establece un mecanismo de acercamiento directo con la víctima para lograr la aceptación de la propuesta realizada (Oficina de las Naciones Unidas contra la Droga y el Delito, 2009 , p. 12). Por su parte, el fraude -que para nosotros es un elemento innecesario debido a la inclusión previa del "engaño"- debe ser concebido, según la doctrina que ha analizado la correspondiente disposición del Protocolo, como la consecuencia lógica del engaño, esto es, la utilización por parte del tratante de la manipulación y la mentira para que la víctima acepte sus ofertas (Oficina de las Naciones Unidas contra la Droga y el Delito, 2009, p. 13). La situación de vulnerabilidad hace referencia a dos circunstancias: primero, que la víctima no tenga capacidad para comprender el significado del hecho (sea menor de edad, incapaz, entre otros); y, segundo, que la víctima no tenga capacidad de resistencia (sea un discapacitado, se encuentre en estado de necesidad económica, ostente bajo nivel cultural, entre otros). Pues bien, el abuso de la situación de vulnerabilidad alude al aprovechamiento del tratante de tales circunstancias para el acercamiento a la víctima y su ulterior control. La concesión de pagos y beneficios significa dar y recibir un beneficio patrimonial como mecanismo por el cual tener el control de la víctima, especialmente, cuando estas son menores de edad y están sujetas por un vínculo legal o parental a otras personas de quienes dependen (Oficina de las Naciones Unidas contra la Droga y el Delito, 2009, p. 10).

Como vimos, la primera fase es la del reclutamiento, la segunda es la fase del transporte. En esta etapa se produce el desplazamiento de la víctima de su lugar de origen. Ahora bien, los medios para hacer eficaz tal conducción son diversos. Puede darse el caso que la explotación de la víctima piense hacerse en el extranjero, caso en el cual pueden existir considerables distancias entre el país de origen y el de destino. Sin embargo, es posible que, por ejemplo, la explotación se realice en el ámbito nacional, "rotando" a la víctima de un lugar a otro de manera periódica. Pues bien, las travesías pueden hacerse por tierra, por mar, como por aire, lo que a su vez permite pensar que el desplazamiento puede ser a través de automóviles, trenes, embarcaciones de todo tipo, e inclusive, aviones.

Ahora bien, en esta fase es posible encontrar los "elementos de actividad", como son el transporte y el traslado. En el ámbito internacional, el traslado ha sido entendido 
como la movilización de una persona de un lugar a otro a través de cualquier medio, por lo que, a diferencia del transporte, el traslado enfatiza el cambio de comunidad o país que realiza una persona (Oficina de las Naciones Unidas contra la Droga y el Delito, 2009, p. 17). En ese sentido, parecería ser que mientras el traslado implica un desplazamiento hacia fuera de las fronteras del país de la víctima, el transporte supone todo lo contrario: una movilización dentro del territorio nacional de la víctima. Por otro lado, en esta fase es posible encontrar también, a nuestro juicio, otros "elementos de actividad" como son la acogida y la recepción. Sobre estos, aunque a primera vista parecerían referirse a lo mismo -el recibimiento de las víctimas-, en el ámbito internacional se ha planteado la posibilidad de hacer una importante diferenciación: mientras la acogida podría aludir al ocultamiento temporal en tanto se reanuda el viaje hacia el destino final, la recepción se referiría al mantenimiento indefinido en el lugar de explotación (Oficina de las Naciones Unidas contra la Droga y el Delito, 2009 , p. 16). Esta distinción, consideramos, podría ser adecuada si se entiende al fenómeno de la trata de personas como un proceso en el que intervienen varias personas y, más aún, si se entiende que el referido fenómeno es una manifestación actual de la criminalidad organizada. Por lo tanto, la realización de la "acogida", en tanto conducta delictiva, podría tener como consecuencia la imposición de una pena -en caso sea contemplada en la legislación interna como modalidad típica en el precepto penal- $y$, por lo tanto, no quedaría impune a pesar de significar un aporte "transitorio" (pues solo alude a un "ocultamiento temporal") por el agente que la lleva a cabo.

En la fase de transporte, según lo señala el Protocolo, también es posible verificar los "elementos de medios". Así, por ejemplo, es posible que la víctima, en medio del traslado, se percate que había sido engañada, ante lo cual el tratante decide amenazarla (le dice que no debe oponerse al traslado pues, de lo contrario, se acabará con la vida de uno de los miembros de su familia) o utilizar la fuerza contra ella (la golpea para amedrentarla y reducir su resistencia).

Finalmente, la tercera fase es la de la explotación. En esta etapa se hace referencia al estadio temporal en el que radica la principal motivación de los tratantes, esto es, rentabilizar su trabajo ilícito sirviéndose, abiertamente, de las personas transportadas como si de medios de producción o mercancías se tratase (Fernández, 2012, p. 108). Por ello, los "elementos de finalidad", que solo acompañan -bajo la forma del "móvil"- a las conductas desplegadas en las fases de reclutamiento y transporte, logran concretarse y hacerse efectivas en la fase de explotación. Pues bien, por explotación debe entenderse a la obtención de beneficios financieros, comerciales o de otro tipo a través de la participación forzada de otra persona en actos de prostitución, servidumbre estatal o laboral, incluidos los actos de pornografía y producción de materiales pornográficos (Oficina de las Naciones Unidas contra la Droga y el Delito, 2009 , p. 12). La esclavitud alude al estado o condición de un individuo sobre el cual se ejercitan los atributos típicamente reconocidos del derecho de propiedad. En ese sentido, la trata de personas comprende todo acto de captura, adquisición o cesión 
de un individuo para ser objeto de compra y venta o, en general, de cualquier acto de comercio (Oficina de las Naciones Unidas contra la Droga y el Delito, 2009, p. 12). La servidumbre es un estado de dependencia o sometimiento de la voluntad en el que el tratante obliga a la víctima a realizar actos, trabajos o servicios a través del uso del engaño, amenazas o la violencia (Oficina de las Naciones Unidas contra la Droga y el Delito, 2009, p. 17). La extracción de órganos alude a la sustracción de un órgano humano sin aplicar los procedimientos médicos básicos, sin el consentimiento de la víctima y para efectos de comercialización (Oficina de las Naciones Unidas contra la Droga y el Delito, 2009, p. 13).

Como es posible observar, la motivación que pone en movimiento las conductas propias del fenómeno de la trata de personas, parece indudablemente residir en la intensa apetencia de satisfacer una inmensa avidez de lucro, esto es, de alcanzar un enriquecimiento amplio y rápido a toda costa. La trata de personas funciona como una verdadera actividad económica, orientada a explotar un "mercado" dentro de un designio de fuerte rentabilidad. Es evidente que se trata de una actividad extraordinariamente lucrativa, teniendo en cuento los bajos costos que supone el inicio de la "empresa" y la relativa debilidad de los riesgos que con tal inicio pueden ser enfrentados (Herrero, 2011, p. 380).

Ahora bien, los "mercados" en los cuales son finalmente situadas las personas objeto de explotación son varios, aunque sin duda el más floreciente es el ligado a la explotación sexual y, particularmente, el referido a la prostitución femenina y de menores (ámbitos que han recibido una mayor atención por parte de la doctrina jurídico-penal). La utilización de mano de obra en el trabajo informal y la mendicidad son las otras dos fuentes importantes de enriquecimiento para las organizaciones criminales: el primero se concretiza en los sectores de las labores domésticas, agrícolas, de la construcción, de la restauración, de los ambulantes y tiene como referencia principalmente las personas de sexo masculino; mientras que, en el segundo, con frecuencia se emplean niños, quienes son obligados a pedir limosna por jornadas enteras en situaciones inhumanas (Herrero, 2011, p. 379).

Tomando en cuenta todos los argumentos expuestos, es posible concluir señalando que, en el ámbito internacional, la trata de personas es entendida como el reclutamiento, transferencia, acogida o recepción de personas, ignorando o neutralizando por cualquier medio el ejercicio de su capacidad de razonar o decidir libremente, dedicándolas durante un determinado espacio temporal prolongado - como si de un simple objeto o mercancía se tratase- a actividades que supongan su explotación sexual o laboral, u obligarlas a cualquier clase de comportamientos que entrañen similar degradación, incluida la aceptación forzada de extracción de órganos. Todo ello -y esto es esencial- por móviles económicos (Herrero, 2011, p. 353). 


\title{
ANÁLISIS DEL TIPO PENAL DE TRATA DE PERSONAS EN EL DERECHO PENAL COLOMBIANO (ARTÍCULO 188-A DEL CÓDIGO PENAL)
}

\author{
El artículo 188-A del Código Penal tiene la siguiente estructura:
}

El que capte, traslade, acoja o reciba a una persona, dentro del territorio nacional o hacia el exterior, con fines de explotación, incurrirá en prisión de trece (13) a veintitrés (23) años y una multa de ochocientos (800) a mil quinientos (1500) salarios mínimos legales mensuales vigentes.

Para efectos de este artículo se entenderá por explotación el obtener provecho económico o cualquier otro beneficio para sí o para otra persona, mediante la explotación de la prostitución ajena u otras formas de explotación sexual, los trabajos o servicios forzados, la esclavitud o las prácticas análogas a la esclavitud, la servidumbre, la explotación de la mendicidad ajena, el matrimonio servil, la extracción de órganos, el turismo sexual u otras formas de explotación

El consentimiento dado por la víctima a cualquier forma de explotación definida en este artículo no constituirá causal de exoneración de la responsabilidad penal.

Pues bien, la estructura del tipo contempla, como primera conducta típica, la conducta de "captar", la cual según el DRAE, significa "atraer a alguien, ganar la voluntad o el afecto de alguien". La mencionada conducta típica -reconocida también, como vimos, en el artículo 3 del Protocolo de Palermo- ha sido definida también como:

un concepto que se traduce en atracción. Es decir, atraer a una persona, llamar su atención o incluso atraerla para un propósito definido. En lo que respecta a la trata de personas tiene un significado muy similar. Presupone reclutamiento de la víctima, atraerla para controlar su voluntad para fines de explotación (Oficina de las Naciones Unidas contra la Droga y el Delito, 2009, p. 3).

El comportamiento consistente en "captar" permite la introducción de la persona tratada en el proceso delictivo de la trata de personas. Así, en esa fase de reclutamiento, los tratantes acuden a distintos métodos para interesar a la víctima en participar de la actividad comercial que se le propone; por ejemplo, la promesa de matrimonio con un extranjero acaudalado o la promesa de mejores condiciones de vida son algunos de los medios fraudulentos empleados por los tratantes para incorporar a las víctimas a la estructura de trata de personas (Aboso, 2013, p. 74). La conducta típica de "captar" también puede abarcar la realización de otras actividades 
como el secuestro u otras formas de coerción, así como el rapto y la falsificación de documentos (Iglesias, 2013, p. 166). Es así como la captación puede producirse a través de mentiras y engaños, mediante los cuales los tratantes interfieren en la voluntad de la víctima, anulándola total o parcialmente con la pretensión de disponer de su autonomía y capacidad de decisión (Observatorio de Trata de Personas de Antioquia, 2013, p. 4). En todo caso, aquí queremos resaltar que, con la realización de la conducta típica de "captar", la víctima pierde la capacidad de controlar su proyecto vital, al adquirir el tratante una clara posición de dominio sobre aquella (Daunis, 2013, p. 82). En ese sentido, consideramos que el núcleo de la conducta típica materia de análisis se corresponde con el hecho de que el sujeto activo logre imponer su voluntad sobre la del sujeto pasivo, imposibilitando que este último ejerza su libertad. Entender de manera amplia el verbo rector “captar", como se propone aquí, permitirá entender que la conducta desvalorada se produce no solo a través de la "atracción" a una persona desconocida que es "reclutada" (escenario, por lo demás, más común), sino también de la selección (ejercida por parte del sujeto activo, que aprovecha su posición de dominio) de una persona conocida (o sobre la que se puede afirmar que existe una estrecha relación, como el caso de los padres con sus hijos) para su entrada en algún contexto coactivo propio de la explotación, en la que su libertad, como es obvio, queda anulada.

Con respecto a la conducta de "trasladar", recogida en el delito tipificado en el art. 188-A del Código Penal, es importante mencionar en primer lugar que, como antes se dijo, en la regulación internacional se han establecido los comportamientos consistentes en "trasportar» y "trasladar". Sin embargo, la figura delictiva reconocida en la legislación penal colombiana solo alude al verbo rector "trasladar". Este comportamiento, según la DRAE, alude al "llevar a alguien o algo de un lugar a otro", lo cual, en el marco del delito de trata de personas debe interpretarse como la realización de una determinada conducta consistente en la concreción del desarraigo de la víctima, esto es, del apartamiento de su lugar de origen. El desarraigo se produce alejando a la víctima de la familia y amigos, desplazándola hacia otro lugar desconocido para ella, donde no cuenta con el apoyo de una red social, no conoce la lengua, ni los agentes sociales o policiales a los que debe dirigirse y, en definitiva, está provista de las principales herramientas o instrumentos para evitar o denunciar su explotación (Daunis, 2013, p. 83). Si es que la conducta típica "trasladar", recogida en el art. 188-A del Código Penal, se entiende de esta manera, poseerá un carácter amplio que permitirá abarcar tanto al "transportar" y al "trasladar", tal y como son entendidas en el art. 3 del Protocolo de Palermo (que, como vimos, suponen conductas que se diferencian únicamente por el alcance de la movilización de la víctima: dentro del territorio nacional y fuera de las fronteras del país, respectivamente). Por otro lado, el desplazamiento de la víctima, según la doctrina, puede llevarse a cabo de diversas formas: en algunos casos se realizará de modo compulsivo y bajo el estricto control de los tratantes, pero en otras circunstancias será la propia víctima quien se traslada, aunque muchas veces siendo controlada por los tratantes (Aboso, 3013, p. 77). 
Ahora bien, es importante tener en cuenta que, desde nuestro punto de vista, la conducta de "trasladar" no solo debería comprenderse como el desplazamiento físico de la víctima de un lugar a otro para la concreción de su desarraigo, sino que también debería albergar la posibilidad de interpretarla como un desplazamiento o traspaso del poder que se ejerce sobre la víctima, esto es, el intercambio o transferencia del control sobre la víctima, por medio de la venta, el alquiler o la permuta de aquella (Villacampa, 2011, p. 418). Consideramos que, atendiendo a la dinámica del fenómeno de trata de personas (en la que la víctima puede mantenerse dominada por sucesivas personas e distintos momentos o tramos del proceso), la conducta típica consistente en "trasladar", recogida en el art. 188-A del Código Penal, debe contemplar la posibilidad de ser interpretada de la manera expuesta.

Con respecto a "acoger" o "recibir" -también señalados, como vimos, de manera expresa en el art. 3 del Protocolo de Palermo-, se afirma que se trata de términos homologables, ya que las mencionadas conductas aluden al manejo de la persona tratada como si fuera una mercancía, lo que puede abarcar el comportamiento consistente en recoger a una persona para llevarla a un punto de tránsito (Observatorio de Trata de Personas de Antioquia, 2013, p. 6). Sin embargo, en la doctrina jurídico-penal se ha planteado algún criterio que permite establecer una diferenciación (aunque sea muy tenue) entre las mencionadas conductas: mientras el "recibir" puede definirse como la admisión física de la víctima, el "acoger" puede suponer el mantener a la víctima en un lugar seguro (Aboso, 2013, p. 79). Es claro que "acoger" se presenta como un verbo rector que puede ser interpretado con amplitud, lo cual permitiría que a través de tal conducta típica se otorgue cobertura a conductas consistentes en dar hospedaje, alojar, esconder o brindar al damnificado protección física (Luciani, 2011, p. 133). Cualquiera de la realización de las mencionadas conductas típicas, implicaría la consumación del delito contemplado en el art. 188-A del Código Penal, sin que necesariamente haya que verificar que la explotación se produjo efectivamente (Daunis, 2013, p. 84). En ese sentido, cabe afirmar que la realización de las conductas de "acoger" o "recibir" no necesariamente significa la finalización del proceso de trata de personas desde una perspectiva socio-criminológica (aquella solo podría afirmarse con la verificación de la explotación de la víctima, instante en el que se concreta su deshumanización o cosificación), aunque sí supone afirmar que se tratan de las últimas conductas cuya realización pueden fundamentar una imputación por el delito de trata de personas (la efectiva explotación sexual de la víctima podrá sostener una imputación por constreñimiento a la prostitución, por ejemplo, en el caso de que la trata se haya realizado con fines de explotación sexual).

El delito de trata de personas posee una estructura compleja y, precisamente por ello, su aplicación práctica puede generar una discusión sobre las propias fronteras del tipo (Londoño y otros, 2012, p. 220). Así, a nuestro modo de ver, es posible que hayan confusiones con estos delitos: inducción a la prostitución (art. 213 del Código Penal), proxenetismo con menor de edad (art. 213-A del Código Penal), constreñimiento a la prostitución (art. 214 del Código Penal), estímulo a la prostitución de menores (art. 217 
del Código Penal), demanda de explotación sexual comercial de personas menores de dieciocho años de edad (art. 217-A del Código Penal), pornografía con menores de dieciocho años (art. 218 del Código Penal), turismo sexual (art. 219 del Código Penal), secuestro (art. 168 del Código Penal), constreñimiento ilegal (art. 182 del Código Penal), tortura (art. 178 del Código Penal) o tráfico de inmigrantes (art. 188 del Código Penal). Aunque no es nuestra intención dedicarnos a esgrimir argumentos sobre la delimitación del delito de trata de personas con las mencionadas figuras delictivas (pues esto supondría exceder el espacio concedido para esta contribución), es importante mencionar que la labor de interpretación del delito de trata de personas debe contemplar la posibilidad de delimitar los alcances de la mencionada figura delictiva y, en ese sentido, distinguir las zonas grises o problemáticas en donde pueda alegarse la concurrencia de los elementos constitutivos de otras figuras delictivas (en las que también se vulnere, por ejemplo, la libertad individual). Un correcto análisis y una adecuada comprensión del delito de trata de personas debe orientarse a evitar la confusión en cuanto a su contenido y límites, pues aquella conduciría infortunadamente a la impunidad o, en todo caso, a la represión penal a través de otras figuras cuya sanción resulta cuantitativamente inferior (Londoño, y otros, 2012, p. 221).

\section{ANÁLISIS DEL TIPO PENAL DE EXPLOTACIÓN DE MENORES EN EL DERECHO PENAL COLOMBIANO (ART. 93 DE LA LEY 1453 DE 2011)}

El delito de explotación de menores está redactado de la siguiente manera:

El que utilice, instrumentalice, comercialice o mendigue con menores de edad directamente o a través de terceros incurrirá en prisión de 3 a 7 años y el menor será conducido al Instituto Colombiano de Bienestar Familiar para aplicar las medidas de restablecimientos de derechos correspondientes.

La pena se aumentará a la mitad cuando el actor sea un pariente hasta el cuarto grado de consanguinidad, segundo de afinidad o primero civil.

Pues bien, la figura delictiva antes citada puede entenderse como un delito común (puede ser cometido por cualquier persona), doloso, de conductas alternativas (será suficiente la realización de cualquiera de los comportamientos descritos) y de resultado (es posible afirmar una distancia espacio-temporal, que, por ejemplo, permite la posibilidad de tentativa). Por otra parte, el delito de explotación de menores tiene un ámbito reducido de sujetos pasivos: los menores de edad. Conociendo tales elementos típicos, es posible abordar lo referido a los verbos rectores en la mencionada figura delictiva. Por "utilizar" puede entenderse el aprovecharse de un menor de edad para pedir limosna, con la finalidad de que aquel despierte una mayor compasión y, consecuentemente, una mayor generosidad en los potenciales donantes 
de dádivas (Torres, 2012, p. 609). Por “instrumentalizar” puede entenderse el empleo del menor de edad "como instrumento" para obtener un determinado fin, en este caso, la compasión de los viandantes. El verbo rector "instrumentalizar" puede evocar, creemos, una cosificación de la persona que se emplea para la consecución de una determinada circunstancia. En el caso del delito materia de comentario, se podría mencionar al escenario en el que el menor de edad es utilizado como medio para alcanzar ganancias. El "comercializar" evoca al hecho de entregar un menor de edad a un tercero para que este se sirva de aquel, percibiendo quien realiza tal entrega una retribución económica. Finalmente, el "mendigar (con menores de edad)" hace referencia a la propia actividad de percepción de dádivas de terceros, a través de la demostración de un estado de postración personal o social (Queralt, 2008, p. 370). Pues bien, como antes se dijo, la realización de cada una de estas conductas por sí misma permitiría la afirmación de la consumación del delito, ya que en la medida que se trata de delitos de resultado de lesión, el cumplimiento de cualquiera de los verbos rectores supondría una lesión del bien jurídico (el que según la Sentencia C-464 de 2014 es "la familia y la libertad") ${ }^{8}$.

Sobre los mencionados verbos rectores podemos afirmar muchas ideas. Así, en primer lugar, es posible preguntarnos: ¿los verbos rectores contemplados en el delito del artículo 39 de la Ley 1453 de 2011 recogen la mendicidad encubierta? (casos en los que los menores de edad son utilizados para realizar venta de productos o para prestar servicios, por ejemplo, la venta ambulatoria de golosinas o el lavado del parabrisas del automóvil en un semáforo en rojo, respectivamente). Esta es una inquietud que debería ser resuelta para determinar con precisión los alcances típicos de la figura delictiva materia de análisis. Al respecto, hasta este momento creemos que la mendicidad encubierta no podría ingresar dentro de los contornos del tipo penal, pues las conductas típicas aluden inequívocamente a la mendicidad realizada de manera manifiesta; además, tomando en cuenta la redacción del precepto, el incluir la mendicidad encubierta podría entenderse como una interpretación excesiva del tipo penal, que casaría mal con el principio de legalidad.

Por otro lado, sobre la conducta de "mendigar con", la Corte Constitucional señaló que, para evitar que se entienda que el artículo 93 de la Ley 1453 de 2011 criminaliza la mendicidad, una persona "no podrá ser perseguida cuando mendigue autónomamente en presencia de menores de edad, sino únicamente cuando utilice o instrumentalice a menores de edad para el ejercicio de la mendicidad". Con ello, como es obvio, no se avanza mucho en la comprensión del tipo, ya que se propone una definición de "mendigar" empleando los otros verbos rectores ("utilizar" e "instrumentalizar"), con lo que no se hace más que ofrecer una argumentación circular. Esta aseveración,

$8 \quad$ Al respecto, la Corte Constitucional señaló sobre el delito de explotación de menores que: "tiene un origen estrictamente nacional, menor riqueza descriptiva e inferior lesividad, además su finalidad concreta radica en brindar una protección exclusiva a los menores de edad en un contexto de seguridad ciudadana". 
entonces, debería llevarnos a pensar en que para definir los alcances del delito de explotación de menores, se debe atender al contenido de las conductas de "utilizar" e "instrumentalizar", sin embargo, tropezamos con el hecho de que (al igual que con la conducta de "mendigar con") la poca precisión de los mencionados verbos típicos, desde nuestro punto de vista, no permite la delimitación entre lo que debe ser punible y lo que debe quedar impune (las conductas mendicantes autónomas realizadas en presencia de menores de edad). En ese sentido, creemos que existen dificultades no solo para distinguir cuándo estamos ante una conducta de "utilizar" y cuándo ante una conducta de "instrumentalizar" (aunque podemos mencionar, de manera intuitiva, sin ánimo de exhaustividad y sin ánimo de postular aquí una posición definitiva, que la diferencia podría radicar en quién recibe la dádiva: el menor de edad y el sujeto activo del delito, respectivamente), sino también para diferenciar cuándo una conducta de "utilizar" o de "instrumentalizar" resultaría jurídico-penalmente relevante: si una mujer, sentada en una acera y con su hijo de meses de nacido en brazos, solicita a los viandantes la dación de una limosna, ¿Estaríamos ante un delito de explotación de menores por "utilización" o "instrumentalización" de menores? Asimismo, si la misma mujer, portando al menor de edad, le dice a un tercero que su hijo está "terriblemente enfermo y que necesita comprarle unas medicinas", ¿se podría afirmar que se produce una "instrumentalización" del menor de edad?

En la realidad resulta frecuente que, por ejemplo, familias enteras se dediquen al ejercicio de la mendicidad. Por ello, no es en absoluto improbable que padres de familia se dediquen a tal actividad acompañados de sus hijos menores de edad. Y aunque se pueda afirmar que, en ocasiones, al no tener más alternativa para sobrevivir, tanto los padres como los hijos menores de edad pueden solicitar dádivas a terceros a través de la demostración pública de su estado de postración personal o social, no se podría afirmar que en tales escenarios siempre existen actos de explotación a los hijos menores de edad por parte de los padres. Sin embargo, es bastante probable que los padres sepan que el ver a menores de edad pidiendo limosnas puede generar un mayor impacto al público, por lo que, aunque no se pueda decir que aquellos están obligados, se podría afirmar que los padres los "utilizan" para percibir dádivas por parte de terceros (tal vez, en una mayor cantidad de la que percibirían si es que no estuvieran acompañados de sus hijos. Es evidente que la presencia de menores de edad en esos contextos genera una mayor compasión en terceros, lo que puede constituirse en un factor que hace posible una mayor recaudación al padre o madre que permite que su hijo menor de edad realice actividades mendicantes). Sin embargo, este escenario, que a nuestro modo de ver, no debería ser reprimido penalmente, puede sin problemas ingresar dentro de los contornos del delito de explotación de menores. Por ello, habría que analizar seriamente si es que acaso, como se sostuvo en la demanda, se admitió en la sentencia y se afirmó en uno de los salvamentos de voto, la incorporación del delito de explotación de menores (que constituiría un claro ejemplo de un derecho penal expansionista ubicado en el contexto de una marcada fragmentación social y con una notoria desigualdad económica) pueda interpretarse 
como un intento de criminalizar la mendicidad, incluso la cometida por los parientes del menor (Velásquez, 2014, p. 170).

Habiendo expuesto algunas consideraciones sobre los elementos típicos del delito de explotación de menores en el derecho penal colombiano, debemos señalar que, desde nuestro punto de vista, la mencionada figura delictiva posee una redacción deficiente, que compromete el respeto al principio de legalidad. Por lo antes expuesto, consideramos que el delito de explotación de menores no otorga los suficientes elementos para una interpretación restrictiva de las actividades merecedoras de represión penal, lo que conduce a afirmar que cualquier actividad de mendicidad podría subsumirse dentro de la mencionada figura delictiva ${ }^{9}$.

Como propuesta de lege ferenda (si es que se considerase como necesaria la vigencia del delito de explotación de menores en el ordenamiento penal colombiano, evidentemente), además de una más adecuada selección de las conductas típicas que integrarían el tipo y de la eventual inclusión de elementos como la violencia o la amenaza, con las cuales cualificar las conductas seleccionadas por el precepto (convirtiéndose este en un delito de medios determinados) y así percibir de manera inequívoca su relevancia jurídico-penal, podríamos proponer la modificación de la estructura del tipo, esto es, de convertirlo de un delito de resultado de lesión (como parece que es en la actualidad el delito del artículo 93 de la Ley 1453 de 2011) a uno de resultado de peligro abstracto, incorporando un elemento subjetivo de tendencia interna trascendente que permita distinguir y cualificar la conducta del sujeto (por ejemplo, una "finalidad de explotación" por parte del sujeto activo). Una modificación en ese sentido no solo permitiría que las conductas jurídicopenales relevantes sean tales precisamente porque el sujeto activo actúa portando una determinada finalidad (que no es necesaria que se concrete, con lo que será suficiente su conducta de "utilización" o "instrumentalización" del menor de edad), sino que las relaciones concursales con el delito de trata de personas se resolverían (en la medida que se trataría de un concurso aparente de leyes), con la aplicación del principio de especialidad (el delito de explotación de menores se aplicaría, por ser lex specialis, en detrimento del delito de trata de personas, que desde la perspectiva de aquel sería una lex generalis). Al modificar la estructura del delito de explotación de menores desde la lógica de un delito de peligro abstracto se produciría, como es obvio, una anticipación de la barrera de intervención penal a estadios previos al consecuente desenlace material (la concreta explotación del menor, por ejemplo), lo cual, a su vez, debería conducirnos al umbral de la discusión sobre la idoneidad del marco penal más adecuado atendiendo al grado de afectación del bien jurídico (el

9 Esto también fue reconocido por la Defensoría del Pueblo, en el marco de la demanda que motivó la Sentencia C-464 de 2014 de la Corte Constitucional. Así esta entidad señaló, con respecto al delito de explotación de menores, que «no ofrece elementos para identificar si estos actos de mendicidad, en presencia de niños o niñas, son derivados de situaciones de extrema necesidad o urgencia manifiesta o efectivamente corresponden a actos de explotación infantil, que a juicio de la entidad, debe constituir el núcleo de este tipo penal». 
principio de lesividad obligaría a que la pena conminada para el delito de explotación de menores responda al esencial dato de que se trata de un delito de peligro abstracto, por lo que no podría reprimirse con un marco penal propio de un delito de resultado material, por ejemplo).

\section{COMENTARIOS SOBRE LOS ARGUMENTOS EXPUESTOS POR LA CORTE CONSTITUCIONAL SOBRE EL DELITO DE TRATA DE PERSONAS Y SU RELACIÓN CONCURSAL CON EL DELITO DE EXPLOTACIÓN DE MENORES}

Habiendo expuesto los aspectos más relevantes de la fenomenología subyacente al delito de trata de personas, y teniendo en cuenta los alcances del respectivo tipo penal en el derecho penal colombiano, proponemos ahora recordar los cuatro argumentos expuestos por la Corte Constitucional en virtud de los cuales admitió la idea de la no confusión típica supuestamente desprendida de la relación entre los delitos de trata de personas y de explotación menores. En primer lugar, se afirmó que entre el delito de trata de personas y el delito de explotación de menores no había una identidad típica en la medida que ambas figuras delictivas se diferenciaban en lo relacionado con el sujeto pasivo: mientras en el delito de trata de personas el sujeto pasivo puede ser cualquier persona, en el delito de explotación de menores el sujeto pasivo puede ser únicamente un menor de edad. Pues bien, desde nuestro punto de vista, esta afirmación no resulta ser absolutamente correcta. Y esto es así porque el delito de trata de personas agravada, recogido en el artículo 188-B del Código Penal, no excluye la posibilidad de que el sujeto pasivo sea menor de edad; inclusive, reconoce este hecho (que el sujeto pasivo sea "menor de 18 años") como circunstancia que fundamenta la agravación del respectivo castigo. En ese sentido, no resulta comprensible que, existiendo un tipo penal (el de trata de personas) cuya penalidad se agrave a partir de la verificación de una determinada condición del sujeto pasivo (que este sea menor de edad), conductas sobre las que se podría alegar una equivalencia lesiva (como las recogidas por el delito de explotación de menores) no sean susceptibles de una represión penal siquiera comparable cuantitativamente. A efectos de confirmar esta apreciación, basta solo con observar la significativa diferencia entre los marcos penales para cada una de las figuras delictivas analizadas (de diez a quince años para el delito de trata de personas, con la posibilidad de aumentar de una tercera parte a la mitad en la medida que concurra la circunstancia agravante, consistente en que la víctima sea menor de edad; y de tres a siete años para el delito de explotación de menores). Al margen de esta desproporcionalidad en la respuesta punitiva que es posible verificar a partir de la comprensión de los tipos penales aquí comentados (sobre lo que se volverá más adelante), consideramos factible desvirtuar el argumento expuesto por la Corte Constitucional: la condición de menor de edad del sujeto pasivo no impide alegar la identidad típica entre los delitos de trata de personas y de explotación de menores, en la medida que en el 
primero de los mencionados es absolutamente posible que un menor de dieciocho años sea sujeto pasivo del delito (y si este es el caso, la pena por imponer se agravaría drásticamente).

Con lo acabado de afirmar tampoco queremos expresar que, de alguna manera, estemos de acuerdo con uno de los argumentos señalados en la demanda, consistente en que "el menor de edad por su condición de especial protección y debilidad manifiesta debería contar con una mayor protección que el adulto" y que "quien en condición de superioridad o confianza se aprovecha del sufrimiento de pesar que produce un niño mendigando (...) resulta necesario que tal conducta reprochable sea sancionada penalmente atendiendo su gravedad, de tal forma que se castigue con más severidad al que mendiga con un menor de edad, que al que mendiga utilizando un adulto". Al respecto, debemos señalar que, al margen de los argumentos que se puedan esgrimir a favor de la idea de que el derecho penal deba proteger más a un menor de edad que a un adulto (la protección del menor de edad, en realidad, debe provenir de todo el ordenamiento jurídico y no solo -o principalmente- del derecho penal, de conformidad a los principios de fragmentariedad y subsidiariedad), aquí nos interesa resaltar lo relacionado con la racionalidad y proporcionalidad de la reacción punitiva, de tal manera que se concentre la atención en escenarios en los que, por ejemplo, por eventuales deficiencias en la imputación (en el ámbito de la práctica judicial), el sujeto activo no sea reprimido por el delito de trata de personas y sí por el de explotación de menores, lo que repercutiría en la imposición de una pena indudablemente inferior, cuestión que podría ser interpretada como un inmerecido tratamiento punitivo más favorable, cuando la conducta (de explotación) es en realidad merecedora de una misma (o, como mínimo, equiparable) respuesta jurídico-penal como la prevista para el delito de trata de personas.

En segundo lugar, la Corte Constitucional afirma que los preceptos penales bajo análisis se diferencian al poseer en sus respectivas estructuras típicas distintos verbos rectores: mientras bajo el delito de trata de personas se reprime las conductas de "captar", "trasladar", "acoger" o "recibir" a una persona (debiendo realizarse las mencionadas conductas con la específica finalidad de explotación de la víctima), por el delito de explotación de menores se castiga las conductas de "utilizar", "instrumentalizar", "comercializar" o "mendigar con" menores de edad. El primer asunto que debe mencionarse aquí es que el delito de trata de personas contempla una serie de conductas que hacen referencia inequívoca a un largo proceso que generalmente debería concluir en la explotación de la víctima. Como es evidente, la estructura del tipo permite la intervención del derecho penal antes de que aquel resultado material se consiga, por lo que no solo se ha optado por una represión alternativa de distintas conductas entendidas como desvaloradas, sino que la realización de cualquiera de aquellas debe implicar una específica motivación, esto es, un fin de explotación de la víctima. Aunque sobre el asunto referido al elemento subjetivo especial que define el delito de trata de personas se regresará más adelante, aquí basta con decir que las conductas típicas recogidas por el mencionado delito, de 
ser vistas desde una perspectiva fenomenológica, constituyen conductas previas a la consecución del objetivo final de la trata de personas (la explotación del individuo). El delito de explotación de menores, por el contrario, no evoca una determinada sucesión de momentos, esto es, una serie de conductas concatenadas que evocan la idea de un proceso. El delito de explotación de menores, tal y como está tipificado en el artículo 93 de la Ley 1453 de 2011, recoge una serie de conductas alternativas que en esencia sugieren la utilización abusiva de un menor de edad para la obtención de un lucro.

Es claro que la Corte Constitucional trata de interpretar el delito de explotación de menores de edad desde la perspectiva de la realidad social colombiana (en la que, al igual que en otros países del orbe, los menores de edad deben realizar actividades de comercio para generar ingresos y así sostener a su familia). Sin embargo, con decir que la actividad que se realiza con la "finalidad de explotar" sí es penalmente relevante pero la que se realiza con la "finalidad de satisfacer sus necesidades mínimas" no lo es, no se le otorga elementos interpretativos suficientes al aplicador de la ley para una adecuada comprensión de la mencionada figura delictiva. Y esto es así pues, a nuestro modo de ver, la frontera entre las finalidades expuestas es de muy difícil determinación. En atención a ello, la resolución de esta compleja situación no pasa por afirmar - como hace la Corte Constitucional-que "la intención del legislador fue sancionar de manera autónoma los actos en los que se utilice un menor de edad para mendigar, sin prescribir formas de mendicidad propia".

En tercer lugar, la Corte Constitucional afirma correctamente que el delito de trata de personas se caracteriza por el elemento subjetivo que debe gobernar las específicas conductas desvaloradas y reconocidas en el tipo penal. Como adecuadamente señala la Corte Constitucional, el mencionado elemento subjetivo no se encuentra en el delito de explotación de menores. Esta ausencia, a nuestro modo de ver, no favorece una adecuada comprensión del fenómeno que se pretende combatir a través del derecho penal: la explotación de menores (especialmente, aquellos casos en que los explotadores son los propios padres u otros familiares de los menores de edad). En el caso del delito de trata de personas, en la doctrina se señala que, al tratarse de un delito de resultado cortado y de tendencia interna trascendente, será suficiente la realización de una de las conductas típicas con la finalidad de explotación. Con ello, se produce una intervención anticipada del derecho penal, el cual, como ya se explicó, no deberá aguardar hasta que se produzca un efectivo resultado material que permita visualizar la explotación de la víctima. Desde nuestro punto de vista (y esto de conformidad a la propuesta de lege ferenda planteada en líneas anteriores), el delito de explotación de menores debería poseer una estructura similar, pues permitiría la intervención anticipada del derecho penal antes inclusive de que los menores de edad realicen efectivamente las actividades mendicantes.

Finalmente, la Corte Constitucional señala que el delito de trata de personas presenta circunstancias que fundamentan una agravación de la pena, cuestión que no posee el delito de explotación de menores. Pues bien, esta afirmación, si bien 
podría conducir a la admisión de la idea de que las mencionadas figuras delictivas constituyen dos distintas, nada dice sobre los ámbitos supuestamente diferenciados en que se aplica cada uno de los delitos en cuestión. En ese sentido, la presunta identidad típica de los delitos de trata de personas y de explotación de menores no se decide por la eventualidad de que por distintos motivos político-criminales se haya destinado una agravación de la respuesta punitiva por la concurrencia de una determinada circunstancia en el marco del proceso de verificación de la existencia de un específico tipo penal, sino que la única forma de desvirtuar aquella presunta identidad debe responder en realidad a determinar los específicos ámbitos de aplicación de cada una de las figuras delictivas, esto es, a la verificación de los elementos que permiten afirmar la existencia de una concreta figura delictiva y no de otra.

\section{APRECIACIÓN FINAL: CONCURSO APARENTE DE LEYES ENTRE EL DELITO DE TRATA DE PERSONAS Y EL DELITO DE EXPLOTACIÓN DE MENORES}

En atención a todo lo expuesto, debemos afirmar que la relación existente entre el delito de trata de personas y el delito de explotación de menores es la de un concurso aparente de leyes, que debe resolverse mediante la aplicación del principio de consunción. Esto quiere decir que, en la medida que el delito de trata de personas incluye el desvalor del delito de explotación de menores, el concurso aparente de leyes existente entre ambas figuras delictivas debe resolverse a favor de la aplicación de la primera de aquellas ${ }^{10}$. Con esta afirmación nos distanciamos de la conclusión de la Corte Constitucional que, al admitir la diferenciación de los ámbitos de proyección de los delitos de trata de personas y de explotación de menores, afirma que entre estas figuras delictivas no existe una "identidad típica". En ese sentido, entendemos que el delito de explotación de menores se encuentra subsumido totalmente en el delito de trata de personas.

Como ha señalado correctamente la Corte Constitucional en la sentencia materia de análisis, el concurso aparente de leyes, en la medida que permite la selección de una de las varias normas presuntamente aplicables, permite evitar la afectación del principio de non bis in ídem, esto es, la múltiple sanción al mismo sujeto por el mismo hecho. Siendo esto así, si tomamos en cuenta los presupuestos básicos expuestos por la Sala de Casación Penal de la Corte Suprema de Justicia (admitidos por la Corte Constitucional en su sentencia), será posible afirmar que, en la medida que el delito de trata de personas y el delito de explotación de menores protegen el mismo bien jurídico (la libertad), el concurso aparente de leyes deberá resolverse a favor de la aplicación del delito de trata de personas, pues este supone que el sujeto activo, al

10 Sobre el principio de consunción como elemento para la resolución de casos de concurso aparente de leyes (Mir Puig, S. (2011). DP. PG. ( $9^{a} e d .$, p. 60). 
momento de realizar la conducta típica, sea portador de una determinada finalidad (que, como es obvio, no es necesaria que se concrete en la realidad), la que en nuestro caso es la finalidad de explotación de la mendicidad ajena.

Esto no debe llevarnos a negar la existencia de un concurso real de delitos cuando, por ejemplo, en el caso del delito de trata de personas con fines de explotación sexual, este resultado se produzca finalmente. De ser esto así, un individuo podría ser penalmente responsable no solo por un delito de trata de personas, sino también, por ejemplo, por el delito de constreñimiento a la prostitución (art. 214 del Código Penal), al tratarse de dos conductas que, si bien pueden ser cometidas por la misma persona, son encuadrables en diversos estadios espacio-temporales del amplio proceso de deshumanización de la víctima que caracteriza a la trata de personas.

Por todo lo expuesto, habrá que afirmar entonces que un individuo que utiliza coactivamente a menores de edad para pedir limosna, debería ser imputado por el delito de trata de personas, al ingresar su conducta dentro de los contornos del elemento "captar", conducta típica que, como antes mencionamos, debería entenderse como la imposición de la voluntad del sujeto activo sobre la del sujeto pasivo, imposibilitando que este pueda ejercer su libertad. En el caso de que el sujeto activo sea, por ejemplo, el padre de familia (que impone con violencia o amenaza a sus hijos la obligación de que realicen prácticas mendicantes), y el sujeto pasivo sea menor de edad, entonces habría un concurso de agravantes, ya que se cumplirían dos escenarios recogidos en el art. 188-B del Código Penal: que el hecho se realice en persona menor de dieciocho años y que el responsable es pariente hasta el tercer grado de consanguinidad. Con este concurso de agravantes, como es evidente, la pena a imponer será más grave. De igual modo, cabe señalar que el sujeto activo no podría afirmar en su favor, por ejemplo, que el menor de edad consintió en realizar las actividades de mendicidad, ya que, como señala el art. 188-A del Código Penal, el consentimiento dado por la víctima a cualquier forma de explotación recogida en el mencionado precepto no constituirá causal de exoneración de la responsabilidad penal.

Si un menor de edad es obligado a mendigar por su padre, y aquel efectivamente lleva a cabo tales actividades, estaremos ante el agotamiento del delito de trata de personas. De conformidad a lo antes señalado, el delito de trata de personas, al ser un delito de tendencia interna trascendente, se estimará consumado con la realización de cualquiera de las conductas típicas recogidas en el precepto (conductas que, como antes se dijo, son alternativas), siempre que con tal realización el sujeto activo porte una determinada finalidad (en el caso del delito de trata de personas, la finalidad de explotación). En ese sentido, regresando al escenario hipotético antes mencionado, el delito de trata de personas se habrá consumado cuando el padre, con la finalidad de explotar a su hijo menor de edad, le hace saber de manera inequívoca sobre su próxima actividad mendicante, ante la cual, evidentemente, el menor de edad no tiene alternativa ni mucho menos capacidad de oposición. 


\section{REFERENCIAS}

Aboso, G. (2013). La criminalidad organizada en la explotación sexual y laboral. La criminalidad organizada en la explotación laboral y sexual. Montevideo: B de F.

Daunis, A. (2013). El delito de trata de seres humanos. Valencia: Tirant lo Blanch.

Fernández, P. (2012). Una aproximación práctica a la lucha contra la trata de seres humanos en España. En García, S., y Fernández, P. La trata de seres humanos (pp. 99-149) Madrid: Centro de Estudios Políticos y Constitucionales.

Herrero, C. (2011). Fenomenología criminal y criminología comparada. Madrid: Dykinson.

Iglesias, A. (2013). La trata de mujeres con fines de explotación sexual: una aproximación político criminal y de género. Buenos Aires: Didot.

Londoño, B., Varón, A., y Luna de Aliaga, B. (2013). El delito de trata de personas: Hacia la aplicación de estándares internacionales para la prevención, judicialización, protección y asistencia integral a las víctimas en Colombia. Revista de Derecho de la Universidad del Norte, 37, 198-230.

Luciani, D. (2011). Criminalidad organizada y trata de personas. Buenos Aires: Rubinzal-Culzoni Editores.

Mir Puig, S. (2011). Derecho penal. Parte general (9 ${ }^{\mathrm{a}}$ ed.). Barcelona: Reppertor.

Nieto, A. (2012). Concurso penal de la trata de seres humanos y utilización de menores como mendigos. Diario La Ley $\mathrm{N}^{\circ}$ 7867, Año XXXIII, referencia: D-219, pp. 1510-1513.

Observatorio de Trata de Personas de Antioquia. (2013). Análisis jurídico-penal del delito de trata de personas, artículo 188-A del Código Penal colombiano.

Oficina de las Naciones Unidas contra la Droga y el Delito. (2009). Manual sobre la investigación del delito de trata de personas. Guía de autoaprendizaje.

Queralt, J. (2008). Derecho penal español. Parte especial. (5 ed.). Barcelona: Atelier.

Rodríguez, T. (2015). Trata de seres humanos y explotación laboral. Reflexiones sobre la realidad práctica. En Alcácer, R., Martín, M. y Valle Mariscal de Gante, M. (Coords.). La trata de seres humanos: Persecución penal y protección de las víctimas (pp. 57-82). Madrid: Edisofer.

Sacha, E. (2012). Aproximación a la trata de personas. En Lara, A. (Dir.) Nuevos retos en la lucha contra la trata de personas con fines de explotación sexual. Pamplona: Thompson Reuters.

Torres, N. (2011). Comentario al artículo 232 del Código Penal español. En Quintero, G. (Dir.) y Morales, F. (Coord.). Comentarios a la parte especial del Código Penal. (9a ed., pp. 607-611). Cizur Menor (Navarra): Thomson Reuters, Civitas.

Velásquez, F. (julio-diciembre, 2014). La trata de personas y la explotación de menores de edad (Comentarios a la Sentencia C-464/14). Cuadernos de Derecho Penal, pp. 121-175. 
Villacampa, C. (2011). El delito de trata de seres humanos. Una incriminación dictada por el Derecho Internacional. Cizur Menor (Navarra): Thompson Reuters, Aranzadi. 